\title{
MENERAPKAN PROGRAM KESELAMATAN PASIEN SEBAGAI BUDAYA YANG TETAP DIJAGA DI RS
}

\author{
SRI HARVITA SARI MARPAUNG / 181101125
}

Sriharvitaaasm11@gmail.com

\begin{abstract}
ABSTRAK
Latar belakang : Penerapan program keselamatan pasien merupakan hal yang sangat penting diterapkan di rumah sakit, namun masih ada beberapa hal yang menjadi faktor penghambat yang mengakibatkan penerapan program keselamatan di RS. Tujuan : diharapkan dapat memberikan informasi mengenai penerapan program keselamatan pasien sebagai budaya yang tetap dijaga di rumash sakit. Metode : menggunakan literature riview berdasarkan teks book, jurnal, e-book (10 tahun terakhir) dengan cara menganalisis, eksplorasi sumber dan kajian bebas. Hasil : memberikan informasi mengenai penerapan program keselamatan pasien sebagai budaya yang tetap dijaga dan diharapkan dapat memberikan informasi mengenai cara penilaian keselamatan pasien di rumah sakit sehingga dalam penerapannya keselamatan pasien tidak dianggap hal asing lagi oleh pemberi layanan kesehatan. Pembahasan : penerapan keselamatan pasien sebagai budaya yang tetap dijaga di rumah sakit, cara mengukur penerapan keselamatan pasien. Kesimpulan : Penerapan keselamatan pasien di rumah sakit merupakan hal yang diprioritaskan dalam pelayanan kesehatan yang diberikan kepada pasien, penerapan program keselamatan pasien harus dapat diterapkan sebagai sebuah budaya yang tetap dijaga dalam sebuah rumah sakit sehingga dalam memberikan pelayanan kesehatan mampu memberikan yang terbaik dan dapat meningkatkan derajat kesehatan pasien. Sebagai budaya keselamatan pasien akan tetap dijaga dan dipelihara sehingga dalam menerapkannya pemberi layanan kesehatan tidak merasa asing lagi.
\end{abstract}

Kata kunci : budaya keselamatan pasien, rumah sakit, pengukur penerapan keselamatan pasien

\section{LATAR BELAKANG}

Ada beberapa faktor yang menjadi penyebab kenapa budaya keselamatan pasien belum benar-benar diterapkan di berbagai rumah sakit. Pertama, rendahnya tingkat kepedulian petugas kesehatan terhadap pasien, hal ini bisa dilihat dengan masih ditemukannya kejadian diskriminasi yang dialami oleh pasien terutama dari masyarakat yang tidak mampu. Kedua, beban kerja petugas kesehatan yang masih terlampaui berat terutama perawat. Perawatlah yang bertanggung jawab terkait asuhan keperawatan kepada pasien sedangkan disisi lain masih ada rumah sakit yang memiliki keterbatasan jumlah perawat yang menjadikan beban kerja mereka meningkat. Ini berdampak pada mutu pelayanan yang tidak sama di setiap rumah sakit. ketiga, orientasi pragmatisme para petugas kesehatan yang saat ini masih melekat disebagian petugas kesehatan. Masih ditemukan para petugas kesehatan yang hanya berorientasi untuk mencari materi/keuntungan semata tanpa mempedulikan keselamatan pasien. Keempat, lemahnya pengawasan yang 
dilakukan oleh dinas kesehatan terhadap para petugas kesehatan.

Keempat hal tersebut diatas yang setidaknya menjadi penghalang terwujudnya budaya keselamatan pasien di setiap rumah sakit. Jika hal ini tidak segera diselesaikan maka kasus-kasus yang mengancam keselamatan pasien akan terus terjadi sehingga perlu upaya yang maksimal untuk mewujudkan budaya keselamatan pasien. Upaya-upaya ini harus segera dilakukan agar tidak ada lagi kasus dugaan malpraktik yang dapat merugikan masyarakat sehingga mutu pelayanan kesehatan di rumah sakit bisa meningkat. Dengan meningkatkan kepedulian terhadap pasien maka dengan mudah budaya keselamatan pasien bisa dijalankan.

\section{TUJUAN}

Tujuan dari penulisan ini adalah diharapkan dapat memberikan informasi mengenai penerapan program keselamatan pasien sebagai budaya yang tetap dijaga di rumash sakit.

\section{METODE}

Metode yang digunakan dalam penulisan ini menggunakan literature riview berdasarkan teks book, jurnal, e-book (10 tahun terakhir) dengan cara menganalisis, eksplorasi sumber dan kajian bebas.

\section{HASIL}

Hasil yang dari penulisan ini adalah memberikan informasi mengenai penerapan program keselamatan pasien sebagai budaya yang tetap dijaga dan diharapkan dapat memberikan informasi mengenai cara penilaian keselamatan pasien di rumah sakit sehingga dalam penerapannya keselamatan pasien tidak dianggap hal asing lagi oleh pemberi layanan kesehatan.

\section{PEMBAHASAN}

Budaya (culture) menurut Stoner diartikan sebagai "gabungan kompleks dari asumsi tingkah laku, cerita,mitos, metafora, dan berbagai ide lain yang menjadi satu untuk menentukan apa arti menjadi anggota masyarakat tertentu". Sedangkan Koentjaraningrat menjelaskan bahwa budaya adalah seluruh total dari pikiran, karya, dan hasil karya manusia yang tidak berakar kepada nalurinya dan karena itu hanya bisa dicetuskan manusia sesudah suatu proses belajar.

Sedangkan keselamatan pasien diartikan sebagai " Suatu sistem dimana RS membuat asuhan pasien lebih aman. Hal ini termasuk: Asesmen risiko, Identifikasi dan pengelolaan hal yang berhubungan dengan risiko pasien, pelaporan dan analisis insiden, kemampuan belajar dari insiden dan tindak lanjutnya, serta Implementasi solusi untuk meminimalkan timbulnya risiko. Sistem ini mencegah 
terjadinya cidera yang disebabkan oleh kesalahan akibat melaksanakan suatu tindakan atau tidak mengambil tindakan yang seharusnya diambil.

Pengukuran budaya Keselamatan Pasien, dapat diukur melalui pengukuran elemen kedua dari model budaya organisasi (Schein, 1999), yaitu espoused values (nilai-nilai pendukung), yang mencakup kepercayaan, nilai-nilai, persepsi dan sikap/attitudeyang berlaku dalam organisasi. Nilai-nilai pendukung ini dianggap lebih mudah diukur, dikenal sebagai iklim organisasi, yang dapat mendiagnosis budaya, sebagai preceding culture dan culture in making.Model dari Flin (2007) menjelaskan bagaimana mekanisme bentuk-bentuk iklim keselamatan (yang digunakan untuk mengukur budaya keselamatan), yang didefinisikan sebagai persepsi terhadap Kejadian Tidak Diharapkan/Adverse Event pada pasien dan pekerja, diukur pada tingkat unit kerja dan organisasi.

Menurut Walshe(2005)dikemukakan bahwa Characteristics of a positive safety culture. Secara garis besar budaya keselamatan pasien dalam organisasi diukur melalui :

- Pola komunikasi menggambarkan saling percaya dan terbuka (communication founded on mutual trust and openness).

- Alir dan proses informasi yang baik ( good information flow and processing).

- Persepsi yang sama tentang pentingnya keamanan/ safety dalam melakukan pelayanan (shared perceptions of the importance of safety).

- Pengakuan terhadap kesalahan/error yang tidak terelakan (recognition of the inevitability of error).

- Keyakinan bahwa pengecekan/ pengukuran keselamatan sebagai tindakan pencegahan yang mujarab (confidence in the efficacy of preventative (safety) measures).

- Identifikasi secara proaktif terhadap ancaman latent keselamatan tindakan (proactive identification of latent threats to safety).

- Organisasi pembelajar (organizational learning).

- Komitmen pimpinan dan ada penanggung jawab program (committed leadership and executive responsibility).

- Pendekatan yang tidak mencari siapa yang salah dan tidak 
memberikan hukuman terhadap laporan dan analisis insiden.

\section{KESIMPULAN}

Penerapan keselamatan pasien di rumah sakit merupakan hal yang diprioritaskan dalam pelayanan kesehatan yang diberikan kepada pasien, penerapan program keselamatan pasien harus dapat diterapkan sebagai sebuah budaya yang tetap dijaga dalam sebuah rumah sakit sehingga dalam memberikan pelayanan kesehatan mampu memberikan yang terbaik dan dapat meningkatkan derajat kesehatan pasien. Sebagai budaya keselamatan pasien akan tetap dijaga dan dipelihara sehingga dalam menerapkannya pemberi layanan kesehatan tidak merasa asing lagi.

\section{REFERENSI}

Anggraeni, D. dkk. (2016). Pengaruh Budaya Keselamatan Pasien Terhadap Sikap Melaporkan Insiden Pada Perawat di Instalasi Rawat Inap Rumah Sakit Tk. II $d r$. Soepraoen. Jurnal Aplikasi Manajemen. 14(2): 309-321.

Astini, A. F. (2016). Gambaran Budaya Keselamatan Pasien di RS Stela Maris Makassar. Prosiding Seminar Nasional Penelitian dan PKM Kesehatan. 2(1): 152-163.
Bawelle, S.C. (2013). Hubungan Pengetahuan dan Sikap Perawat dengan Pelaksanaan Keselamatan Pasien (Patient Safety) di Ruang Rawat Inap RSUD Liun Kendage Tahune. e-Journal Keperawatan. 1(1):1-7.

Elfrida, S. (2011). Budaya Patient Safety dan Karakteristik

KesalahanPelayanan: Implikasi Kebijakan di Salah Satu Rumah Sakit di Kota Jambi. Jurnal Kesehatan Masyarakat Nasional. 6(2): 67-76.

Fitriana, Y. \& Pratiwi, K. (2018). Pelaksanaan Patient Safety di Rumah Sakit Umum Daerah dan Rumah Sakit Umum Swasta Bantul Berdasarkan Ketentuan UndangUndang Nomor 44 Tahun 2009 Tentang Rumah Sakit. Jurnal Kebidanan. 7(1):28-39.

Harus, B. D. \& Sutriningsih, A. (2015). Pengetahuan Perawat Tentang Keselamatan Pasien dengan Pelaksanaan Prosedur Keselamatan Pasien Rumah Sakit (KPRS) di Rumah Sakit Panti Waluya Sawahan Malang. Jurnal CARE. 3(1): 25-32. 
Iriviranty, A. (2015). Analisis Budaya Organisasi dan Budaya Keselamatan Pasien Sebagai Langkah Pengembangan Keselamatan Pasien di RSIA Budi Kemuliaan Tahun 2014. Jurnal Administrasi Rumah Sakit. 1(3): 196-206.

Najihah. (2018). Budaya Keselamatan Pasien dan Insiden Keselamatan Pasien di Rumah Sakit : Literature Review. Journal Of Islamic Nursing. 3(1): 1-8.

Pujilestari, A. dkk. (2014). Budaya Keselamatan Pasien di Intalasi Rawat Inap RSUP DR. Wahidin Sudirohusodo Kota Makassar. Jurnal MKMI. 57-64.

Simamora, R. H. (2019). Buku Ajar Pelaksanaan Identifikasi Pasien. UWAIS:Inspirasi Indonesia.
Simamora, R. H. (2019). Documentation of patient Identification into the Electronic System to improve the quality of nursing services. Internasional Journal of Scientific \& Technology Reasearch.

Simamora, R. H. (2019). The influence Of Training Handover based SBAR Communication for improving patients Safety. Indian journal of public Health Reserch \& Development.

Tristantia, A. D. (2018). Evaluasi Sistem Pelaporan Insiden Keselamatan Pasien di Rumah Sakit. Jurnal Administrasi Kesehatan Indonesia. 6(2): 83-94.

Yasmi, Y. \& Hasbullah T. (2018). FaktorFaktor yang Berhubungan dengan Budaya Keselamatan Pasien di Rumah Sakit Karya Bhakti Pratiwi 